\title{
Densidade de plantas e métodos de colheita na multiplicação de batata- semente em vasos
}

\author{
Ricardo M Corrêa; José Eduardo BP Pinto; Érika S Reis; Aline B Monteiro; César Augusto BP Pinto; \\ Valdemar Faquin
}

UFLA, C. Postal 3037, 37200-000 Lavras-MG; ricardomonc7@yahoo.com.br

\begin{abstract}
RESUMO
Por apresentar volume limitado de substrato, o plantio em vasos pode levar a uma reduzida taxa de multiplicação de tubérculos de batata. Objetivou-se estudar a multiplicação de tubérculos-semente pré-básicos de batata em vasos, em função da densidade de plantas e dos métodos de colheita. Os ensaios foram conduzidos em ambiente protegido com tela antiafídeo, em vasos de $3 \mathrm{~L}$. Em ambos os ensaios foram utilizadas plântulas livres de vírus. No primeiro ensaio foram avaliadas as cultivares Monalisa e Ágata e dois métodos de colheita (única e escalonada, com colheitas a cada 30 dias), em um fatorial $2 \times 2$ em delineamento inteiramente ao acaso, com seis repetições e parcelas de quatro vasos, com uma plântula por vaso. No segundo ensaio, foi utilizada apenas a cultivar Monalisa e foram avaliadas cinco densidades de plantio, de 1 a 5 plantas por vaso ( 25 a 125 plantas $\mathrm{m}^{-2}$ ) nas épocas de primavera/verão e outono/inverno. Estes ensaios foram conduzidos em delineamento inteiramente ao acaso, com quatro repetições de quatro vasos cada. Não houve efeito significativo do método de colheita sobre o número total de brotos. Ao contrário, maior comprimento e massa fresca de tubérculos foram obtidos na colheita única. A cultivar Ágata produziu significativamente mais tubérculos por planta que a cultivar Monalisa, embora esta tenha produzido tubérculos de maior comprimento e massa. Em relação à densidade de plantio, na primavera/verão cada planta adicionada ao vaso $\left(0,04 \mathrm{~m}^{2}\right.$ para cada planta adicionada) proporcionou um incremento de 2,69 tubérculos por vaso $(67,25$ tubérculos $\mathrm{m}^{-2}$ ), enquanto, no inverno, o incremento foi de 4,36 tubérculos por vaso (109 tubérculos $\mathrm{m}^{-2}$ ). Por outro lado, o aumento na densidade levou à redução em média de 3,20 g na massa fresca dos tubérculos para cada planta adicionada ao vaso no experimento de inverno. No experimento conduzido na primavera/verão a densidade de plantio não influenciou o peso fresco dos tubérculos.
\end{abstract}

Palavras-chave: Solanum tuberosum L., semente pré-básica, número de plantas por vaso, escalonamento de colheita.

\begin{abstract}
Plant density and harvest methods for potato seed tuber multiplication in pots

The limited volume of substrate might reduce tuber multiplication rates when production is carried out in pots. The results of potato seed tubers multiplication in pots are presented in this publication, taking into account different plant densities and harvest methods. Experiments were carried out in an aphid-proof screenhouse, with 3 L pots, using virus-free seedlings previously acclimatized. In the first experiment, cultivars Monalisa and Agata, and two harvest systems were evaluated (single destructive and sequential 30-day intervals non-destructive harvests) in two seasons, namely spring/ summer and autumn/winter. The experimental design was completely randomized, in a $2 \times 2$ factorial scheme, with six replications, fourpot plots and one seedling per pot. In the second experiment, potato seedlings from cultivar Monalisa were transplanted to pots according to the density treatments, from 1 to 5 seedlings per pot ( 25 to 125 plants $\mathrm{m}^{-2}$ ). The experiment was carried out in a completely randomized design with four replications and four-pot plots. Larger tuber yield per plant was obtained under non-destructive harvest for both cultivars. Instead, larger tuber length and fresh weight were observed in the single destructive harvest. Cultivar Agata outyielded cultivar Monalisa in number of tubers, although the latter produced longer and heavier tubers. Regarding plant density, each additional plant per pot $\left(0.04 \mathrm{~m}^{2}\right.$ per plant), yielded 2.69 extra tubers per plant) (67.25 tubers $\mathrm{m}^{-2}$ ) in the spring/summer experiment and 4.36 extra tubers (109 tubers $\mathrm{m}^{-2}$ ) in the winter experiment. Nevertheless, the increase in density led to an average decrease of $3.20 \mathrm{~g}$ in tuber fresh weight per additional plant. In the spring/summer experiment, plant density had no significant influence on tuber fresh weight.
\end{abstract}

Keywords: Solanum tuberosum L., potato seed tuber, number of plants per pot, non-destructive harvest.

\section{(Recebido para publicação em 01 de setembro de 2005; aceito em 20 de maio de 2007)}

\begin{abstract}
$\mathrm{A}$ semente é uma unidade que merece atenção especial em toda a cadeia produtiva da batata, pois, a partir da sua qualidade, do seu potencial e vigor é que se vislumbra e se persegue a oportunidade de atender ao consumidor com produtos de melhor qualidade e preço (Paes \& Silva, 2003). Desta forma, é essencial buscar sistemas eficientes de produção de batata-semente visando à redução do seu custo de produção e mantendo sua qualidade fisiológica. Atualmente, existem diversos re-
\end{abstract}

cipientes para plantio de tubérculos-semente como vasos, sacos plásticos, bandejas de isopor ou materiais biodegradáveis. Estes recipientes, quando associados a substratos com boa capacidade de drenagem e retenção de água, proporcionam altas produtividades em sistemas de telado ou estufa (Ferreira \& Bittencourt, 2003).

Diversos são os estudos de produção de batata-semente em vasos (Lommen \& Struik, 1992; Lommen, 1995; Ahloowalia, 1999; Grigoriadou \&
Leventakis, 1999; Nowak et al., 1999; Assis et al. 2000). Lommen (1995), estudando os fatores básicos na produção e desempenho de tubérculos de batata, utilizou vasos de plástico em seus ensaios em casa-de-vegetação e verificou que a colheita escalonada comprometia o sistema radicular, levando à quebra de dominância apical (acarretou mudanças no particionamento de fotoassimilados) e estresse nas raízes (compromete a absorção de água e posterior desenvolvimento da planta). Lommen \& Struik 
(1992), no trabalho de produção de tubérculos de batata em vasos em função de várias colheitas, também observaram efeitos negativos do método de colheita escalonada na produção de tubérculos, indicando que as plantas completaram o ciclo rapidamente, devido às condições adversas como temperatura elevada, densidade de plantas e a própria colheita escalonada, que danificou o sistema radicular e acelerou a senescência das plantas.

A densidade de plantas por vaso é também fator importante na produção de batata-semente em vasos. Lommen (1995) utilizou seis plantas por vaso, na tentativa de obter alta densidade de plantas (350 plantas $\left.\mathrm{m}^{-2}\right)$. Augustin (2004), utilizando diversos substratos à base de casca de arroz, verificou que a densidade de seis plantas por vaso era exatamente a densidade que proporcionava a maior produção média de tubérculossemente por vaso. Já Roettger (1987) relata que, a produção de batata-semente nas Filipinas é feita utilizando vasos de $3 \mathrm{~L}$, com densidade de quatro plantas por vaso.

O objetivo do presente trabalho foi estudar a produção de sementes pré-básicas de batata em vasos, em função do método de colheita e da densidade de plantas.

\section{MATERIAL E MÉTODOS}

Os ensaios foram conduzidos em laboratório na Universidade Federal de Lavras (UFLA), de junho a dezembro de 2003. Foram utilizados nos ensaios as cultivares Monalisa e Ágata. As plântulas pré-estabelecidas em cultura de tecidos (isentas de viroses pelo teste de indexação), com cerca de 4 a $6 \mathrm{~cm}$ de comprimento, foram retiradas dos frascos $(300 \mathrm{~mL})$ e aclimatadas em bandejas de isopor com o substrato Plantmax $^{\circledR}$. A aclimatação foi feita em casa-de-vegetação sob sombrite e com irrigação por aspersão, elevando-se gradativamente a luminosidade e reduzindo a irrigação. Em ambos os ensaios, os dados obtidos foram analisados estatisticamente utilizando-se o aplicativo SISVAR, versão 4.3 (Ferreira, 2000).

Ensaio I: Métodos de colheita Foi realizado na época de inverno na região sul de Minas Gerais (junho a agosto de 2003). As plântulas foram transplantadas em vasos de 3 L (1 plântula por vaso), colocados em canteiros suspensos de alvenaria, no interior de uma casade-vegetação com tela antiafídeo. O substrato utilizado nos vasos foi Plantmax $x^{\hat{a}}$ ocupando aproximadamente $70 \%$ do volume, sendo o restante reservado para a amontoa. Os vasos foram dispostos lado-a-lado, de forma a manter um espaçamento de $20 \mathrm{~cm}$ entre plantas (distância entre o ponto médio de cada vaso). Após 10 dias, foi realizada a adubação de cobertura com sulfato de amônio (5 $\left.\mathrm{g} \mathrm{vaso}^{-1}\right)$, juntamente com a amontoa. $\mathrm{O}$ delineamento experimental foi inteiramente casualizado, com seis repetições, cada uma composta por quatro vasos. Os tratamentos foram arranjados em um fatorial 2 x 2 , correspondendo às cultivares Monalisa e Ágata e a dois métodos de colheita (único e escalonado). Na colheita única todos os tubérculos foram colhidos no final do ciclo, 90 dias após o plantio. As colheitas escalonadas foram realizadas 30, 60 e 90 dias após o plantio. Na colheita escalonada, as plantas foram retiradas cuidadosamente do substrato e os tubérculos maiores que $2 \mathrm{~cm}$ foram colhidos. Posteriormente, as plantas foram colocadas novamente nos vasos para que fosse efetuada a próxima colheita em 30 dias. Os tubérculos, depois de colhidos, foram tratados com thiabendazol e kazugamicina e armazenados em câmara fria sob temperatura de $4^{\circ} \mathrm{C}$ e umidade relativa de $90 \%$. Ao final do experimento foram analisados o número de tubérculos por planta e o comprimento e massa fresca dos tubérculos.

Após cinco meses de armazenamento, os tubérculos foram retirados da câmara fria para avaliação da brotação. O teste de brotação consistiu em colocar os tubérculos em local ventilado, com luz difusa, em caixas de papelão suspensas de $30 \times 30 \times 30 \mathrm{~cm}$ a $20 \mathrm{~cm}$ do piso. $\mathrm{O}$ delineamento experimental foi inteiramente casualizado com três repetições de 50 tubérculos cada, mantendo-se os mesmos tratamentos utilizados para produção dos tubérculos. As brotações foram avaliadas 30 dias após a retirada dos tubérculos da câmara fria, contando-se o número de brotos por tubérculo e medindo o comprimento dos respectivos brotos.

Ensaio II: Densidade de plantas O ensaio foi conduzido em duas épocas distintas: a) primavera/verão de 2003 (setembro a dezembro), em temperaturas mais elevadas e b) outono/inverno de 2004 (maio a julho). Plântulas da cultivar Monalisa aclimatadas foram transplantadas para vasos de $3 \mathrm{~L}$, colocados em canteiros de alvenaria suspensos em casa-de-vegetação com tela antiafídeos. Neste experimento, utilizou-se sombrite $50 \%$ acima das plantas. O enchimento dos vasos e a adubação foram executados conforme relatado no primeiro ensaio. O delineamento experimental utilizado foi inteiramente casualizado, com quatro repetições e parcelas de quatro vasos. Os tratamentos corresponderam a densidades de plantio, de uma a cinco plantas por vaso (25 a 125 plantas $\mathrm{m}^{-2}$ ). A colheita foi realizada ao final do ciclo (colheita única). Foram analisados o número total de tubérculos por vaso e comprimento e massa fresca dos tubérculos.

\section{RESULTADOS E DISCUSSÃO}

Métodos de colheita A interação cultivar x método de colheita foi significativa $(\mathrm{p}<0,05)$ para número de tubérculos por planta. Ainda assim, verificouse que o número de tubérculos produzidos foi superior na colheita escalonada em comparação com a colheita única para ambas as cultivares (Tabela 1). A significância da interação deveu-se à magnitude da resposta das cultivares ao método de colheita: enquanto a cultivar Monalisa produziu, em média, o dobro de tubérculos na colheita escalonada em relação à colheita única, 12,4 e 6,2 tubérculos planta $^{-1}$, respectivamente. A cultivar Ágata produziu, em média, $60 \%$ mais tubérculos na colheita escalonada (12,5 tubérculos planta $\left.{ }^{-1}\right)$ do que na colheita única $\left(7,8\right.$ tubérculos planta $\left.{ }^{-1}\right)$.

O comprimento dos tubérculos e a massa fresca também foram influenciados pela cultivar e método de colheita $(\mathrm{p}<0,05)$. Com a colheita única observaram-se tubérculos de maior comprimento médio e massa fresca mais elevada para ambas as cultivares em comparação à colheita escalonada (Tabela 1). A 
Tabela 1. Número total de tubérculos planta ${ }^{-1}$, comprimento médio e massa fresca média de tubérculos de batata conduzidos em vasos em função de cultivares e métodos de colheita (Total number of tuber plant ${ }^{-1}$, average length and fresh weight of potato tubers planted in pots as a result of cultivars and harvest methods) Lavras, UFLA, 2003.

\begin{tabular}{|c|c|c|c|c|c|c|c|}
\hline \multirow[t]{2}{*}{ Colheita } & \multicolumn{3}{|c|}{$\begin{array}{l}\text { Número total de } \\
\text { tubérculos/planta }\end{array}$} & \multicolumn{2}{|c|}{$\begin{array}{l}\text { Comprimento do } \\
\text { tubérculo }(\mathrm{cm})\end{array}$} & \multicolumn{2}{|c|}{$\begin{array}{c}\text { Massa fresca do } \\
\text { tubérculo }(\mathrm{g})\end{array}$} \\
\hline & Monalisa * & Ágata & Média & Monalisa & $\overline{\text { Ágata }}$ & Monalisa & Ágata \\
\hline Única & $6,2 \mathrm{bB}$ & $7,8 \mathrm{bA}$ & 7,0 & $4,7 \mathrm{aA}$ & $3,7 \mathrm{aB}$ & $27,3 \mathrm{aA}$ & $16,1 \mathrm{aB}$ \\
\hline escalonada & 12,4 aA & $12,5 \mathrm{aA}$ & 12,5 & $3,7 \mathrm{bA}$ & $3,0 \mathrm{bB}$ & $10,5 \mathrm{bA}$ & $8,0 \mathrm{bA}$ \\
\hline Média & 9,3 & 10,2 & & 4,2 & 3,4 & 18,9 & 12,1 \\
\hline$\overline{C V}(\%)$ & \multicolumn{2}{|c|}{17,09} & & \multicolumn{2}{|c|}{11,25} & \multicolumn{2}{|c|}{18,52} \\
\hline
\end{tabular}

Médias seguidas de mesma letra minúscula na coluna e maiúscula na linha, para cada variável resposta, não diferem entre si, teste de Tukey, $\mathrm{p}<0,05$ (Means followed by the same small letter in the column and capital letter in the row, for each variable, did not differ from each other, Tukey's test, $\mathrm{p}<0,05)$.

Tabela 2. Número total de brotos tubérculo ${ }^{-1}$ e comprimento de brotos de tubérculos de batata após cinco meses de armazenamento (Total number of sprouts tuber ${ }^{-1}$ and sprout length in potato tubers after five months of storage). Lavras, UFLA, 2003.

\begin{tabular}{|c|c|c|c|c|}
\hline \multirow{3}{*}{ Colheita } & \multicolumn{2}{|c|}{ No. de brotos tubérculo-1 } & \multicolumn{2}{|c|}{ Comprimento de brotos $(\mathrm{cm})$} \\
\hline & \multicolumn{4}{|c|}{ Cultivar } \\
\hline & Monalisa & Ágata & Monalisa & Ágata \\
\hline Única & $2,80 \mathrm{a}$ & $2,20 a$ & $0,8 \mathrm{a}$ & $1,0 \mathrm{a}$ \\
\hline Escalonada & $2,77 \mathrm{a}$ & $2,33 a$ & $0,6 a$ & $0,8 a$ \\
\hline
\end{tabular}

Médias seguidas de mesma letra na coluna, para cada variável resposta, não diferem entre si, teste Tukey, $\mathrm{p}<0,05$ (Means followed by the same letter in the column, for each variable, did not differ from each other, Tukey's test, $\mathrm{p}<0,05) ;$ * Média de brotos de 50 tubérculos. Para a colheita escalonada, o número de brotos por tubérculo refere-se aos valores médios das colheitas de 30, 60 e 90 dias. Análise realizada sobre valores transformados para $(x+1)^{1 / 2}$ (Average number of sprouts for 50 tubers. For the sequential harvest, the number of sprouts tubers $^{-1}$ refers to the average value between the harvests carried out 30,60, and 90 days after planting. Analysis was performed over values transformed to $\left.(x+1)^{1 / 2}\right)$.

cultivar Monalisa produziu tubérculos mais compridos e de massa fresca mais elevada que a cultivar Ágata nos dois métodos de colheita (Tabela 1). Resultados semelhantes foram obtidos por Lommen (1995) com as cultivares Ostara e Bintje cultivadas em vasos plásticos.

A possível explicação para a maior produção de tubérculos por planta na colheita escalonada está relacionada à relação fonte-dreno e ao estímulo à tuberização. De acordo com Lommen (1995), na colheita única, os fotoassimilados são direcionados para o crescimento dos tubérculos, que são colhidos somente ao final do ciclo. Com isto, as plantas podem desenvolver os tubérculos por todo o ciclo, originando assim menor número de tubérculos, mas com maior peso e diâmetro. Já na colheita escalonada, com a retirada parcial dos tubérculos ao longo do ciclo, as reservas que seriam destinadas ao seu crescimento são direcionadas para formação de novos tubérculos (Lommen, 1995). Além deste particionamento de fotoassimilados, ocorre também o estímulo à tuberização com a retirada parcial de tubérculos, sendo as plantas induzidas a produzirem novos tubérculos. Desta forma, os tubérculos produzidos na colheita escalonada serão em maior quantidade, mas de menor peso e diâmetro.

Em relação à avaliação da brotação de tubérculos, observou-se que não houve efeito dos métodos de colheita, para ambas as cultivares, para o número total de brotos tubérculo ${ }^{-1}$. No entanto, como foram realizadas três colheitas escalonadas ao longo do ciclo, o rendimento de tubérculos e conseqüentemente o número total de brotos foi maior na colheita escalonada (três vezes maior) que na colheita única. Para o comprimento de brotos, não foi observada di- ferença significativa entre a colheita única e a escalonada (Tabela 2).

Densidade de plantas No inverno, a densidade de plantas por vaso influenciou linear e significativamente a produção de tubérculos da cultivar Monalisa $(\mathrm{p}<0,05)$. Observou-se um acréscimo de 4,4 tubérculos por vaso (109 tubérculos $\mathrm{m}^{-2}$ ) para cada planta adicional no vaso $\left(0,04 \mathrm{~m}^{2}\right.$ planta adicional no vaso-1) (Figura 1). A massa fresca de tubérculos também foi influenciada significativamente pelo número de plantas por vaso $(\mathrm{p}<0,05)$. A cada planta adicional no vaso, observou-se um decréscimo de 3,2 g na massa fresca dos tubérculos (Figura 1). Não houve efeito significativo da densidade de plantas por vaso sobre o comprimento dos tubérculos que ficou, em média, em 3,4 cm.

No experimento conduzido na primavera/verão, a densidade de plantas por vaso influenciou linear e significativamente a produção de tubérculos da cultivar Monalisa $(\mathrm{p}<0,05)$, ocorrendo um acréscimo de 2,7 tubérculos por vaso $\left(67,25\right.$ tubérculos $\left.\mathrm{m}^{-2}\right)$ para cada planta adicional no vaso $\left(0,04 \mathrm{~m}^{2}\right.$ planta adicional no vaso-1 ${ }^{-1}$ (Figura 2). Porém, a densidade de plantas por vaso não influenciou significativamente a massa fresca de tubérculos $(\mathrm{p}<0,05)$. A média geral foi de tubérculos com $8,3 \mathrm{~g}$.

O maior número de tubérculos por vaso observado à medida que a densidade de plantas aumentou pode ser explicado pela competição entre as plantas dentro de cada vaso. Com uma planta por vaso, não há competição interplanta, sendo os nutrientes do substrato, água e os demais recursos integralmente disponíveis a uma única planta. À medida que o número de plantas no vaso aumenta, introduz-se a competição entre plantas, que será tanto maior quanto maior for o número de plantas. Resultados semelhantes foram obtidos por Gupta et al. (2003), que utilizando plantas micropropagadas, observaram que uma alta densidade de plantas (86 plantas $\mathrm{m}^{-2}$ ) proporcionou a produção, em média, de 5,9 tubérculos planta $^{-1}$, ao passo que, em uma densidade menor (36 plantas $\mathrm{m}^{-2}$ ), a produção foi de 5,3 tubérculos planta ${ }^{-1}$ (diferença de $11 \%$ ).

O ensaio de primavera/verão foi conduzido em época atípica para a produ- 

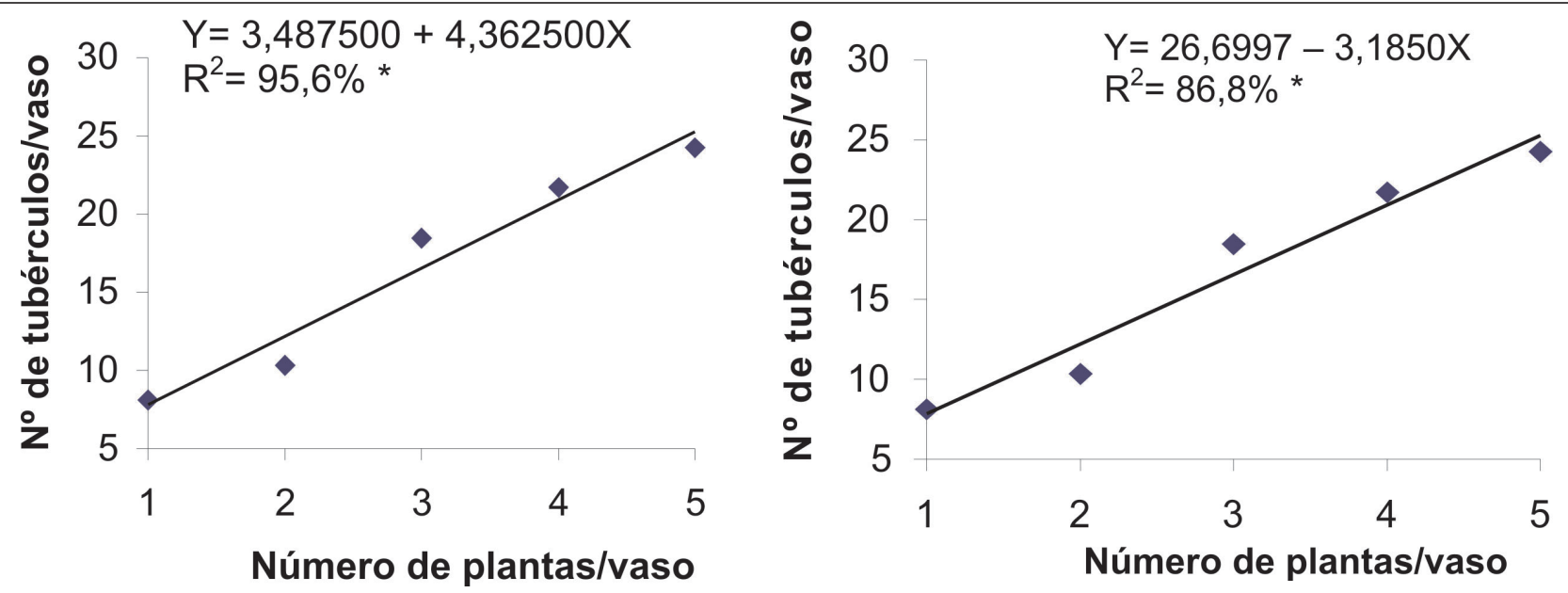

* Significativo, a $5 \%$, pelo teste $\mathrm{F}$.

Figura 1. Número de tubérculos vaso ${ }^{-1}$ e massa fresca de tubérculos da cultivar Monalisa em função da densidade de plantas vaso ${ }^{-1}$, em experimento conduzido no inverno (Number of tubers pot $^{-1}$ and tuber fresh weight for cultivar Monalisa as affected by plant density pot ${ }^{-1}$, in the winter experiment). Lavras, UFLA, 2003 (* Significativo, teste F, p < 0,05 - significant, F test, p < 0.05).

ção de batata na região de Lavras, visto que as temperaturas nestas estações são geralmente elevadas. Durante o dia, no interior do telado onde as plantas foram conduzidas, a média de temperatura atingiu valores de $35 \mathrm{a} 40^{\circ} \mathrm{C}$, mesmo as plantas estando debaixo de sombrite $50 \%$ de iluminação. Souza (2003) relata que a temperatura ótima para a formação de tubérculos é de $17^{\circ} \mathrm{C}$ e que acima de $28^{\circ} \mathrm{C}$ não há formação de tubérculos. As temperaturas noturnas amenas (em torno de $20^{\circ} \mathrm{C}$ ) são importantes também para a tuberização, visto que a planta de batata necessita de um gradiente de temperatura diurno/noturno em torno de $10^{\circ} \mathrm{C}$ para as ativações enzimática e hormonais relacionadas à tuberização. Em contrapartida, no presente trabalho, mesmo com temperaturas diurnas acima de $28^{\circ} \mathrm{C}$, ocorreu a formação de tubérculos, muito provavelmente devido ao gradiente de temperatura ocorrido entre o dia e a noite.

Considerações gerais A produção de tubérculos por planta e por $\mathrm{m}^{2}$ das cultivares Monalisa e Ágata foi maior na colheita escalonada em comparação à colheita única. Já o comprimento médio e a massa fresca de tubérculos foram maiores na colheita única que na colheita escalonada, para ambas as cultivares. O número total de brotações por tubérculo não foi influenciado pelo método de colheita.

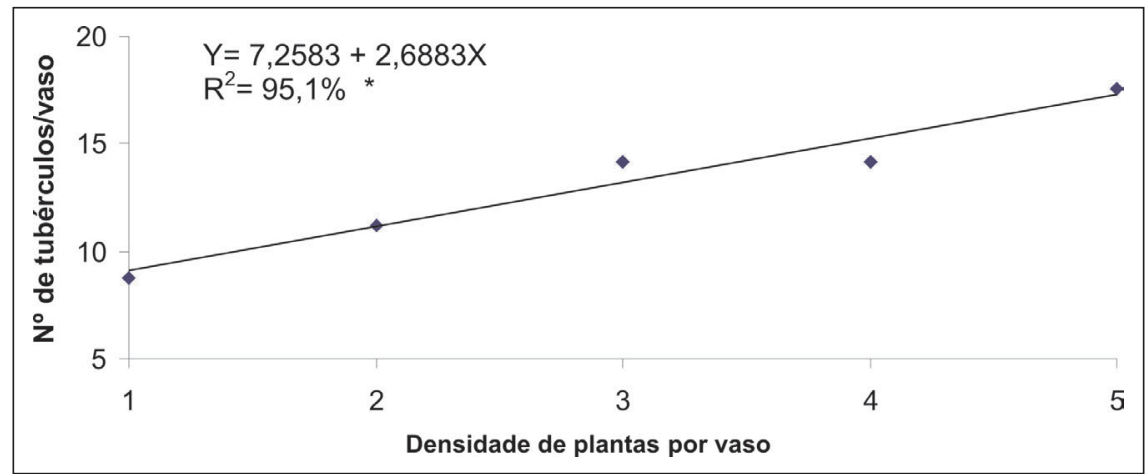

Figura 2. Número de tubérculos vaso ${ }^{-1}$ e da cultivar Monalisa em função da densidade de plantas vaso ${ }^{-1}$, em experimento conduzido na primavera/verão (Number of tubers pot ${ }^{-1}$ and tuber fresh weight for cultivar Monalisa as affected by plant density pot $^{-1}$, in the winter experiment). (* Significativo, te teste F, p $<0,05$ - significant, F test, $\mathrm{p}<0.05$ ). Lavras, UFLA, 2003

Variações na densidade de plantio foram estudadas apenas para a cultivar Monalisa. Observou-se que a produção de tubérculos vaso ${ }^{-1}$ aumentou de forma linear à medida que aumentou a densidade de plantas vaso ${ }^{-1}$. Por outro lado, no inverno, a massa fresca de tubérculos decresceu de forma linear com o aumento da densidade de plantas vaso ${ }^{-1}$, embora, na primavera/ verão, a densidade de plantio não tenha apresentado efeito significativo sobre a massa fresca dos tubérculos.

\section{AGRADECIMENTOS}

Á FAPEMIG pelo auxílio financeiro ao projeto e à CAPES pela concessão de bolsa ao primeiro autor.

\section{REFERÊNCIAS}

AHLOOWALIA BS. 1999. Production of minitubers using a modular system of plant micropropagation. Potato Research 42: 569-575.

ASSIS M; PAIVA M; ARMANI OC. 2000. Micropropagação de plantas: histórico de uma empresa comercial. Informe Agropecuário 21: 124-126.

AUGUSTIN L; VALENDORFF ALP; SUZIN M; GRANDO MF; FIOREZE I; CALVETE EO; KLEIN VA. 2004. Diferentes substratos no sistema de produção de batata-semente pré-básica, em estufa climatizada. In: ENCONTRO NACIONAL SOBRE SUBSTRATO PARA PLANTAS (ENSUB), 4. Anais... Viçosa: UFV. p. 346.

FERREIRA FF; BITTENCOURT MLC. 2003. Novos métodos aplicados à produção de batata-semente. In: SEMINÁRIO MINEIRO DE BATATICUlTURA, 4. Anais... Poços de Caldas: Editora Gráfica Irmão Gino. p. 121-124. 
GRIGORIADOU K; LEVENTAKIS N. 1999 Large scale commercial production of potato tubers, using in vitro techniques. Potato Research 42: 607-617.

GUPTA VK; KUMAR S; BAISHVA LK KUMAR M; PANDEV SK; BRAJESH S. 2003. Effect of planting density on mini-tuber production from micropropagation plants. Journal of the Indian Potato Association 30: 43-44.

LOMMEN WJM. 1995. Basic studies on the production and performance of potato tubers. Wageningen: Landbouw Universiteit. 181p. (Ph.D. Thesis).
LOMMEN WJM; STRUIK PC. 1992. Influence of a single non-destructive harvest on potato plantlets grown for tuber production. Netherlands Journal of Agricultural Science 40: 21-41.

NOWAK J; BENSALIM S; SITH CD; DUNBAR C; ASIEDU SK; MADANI A; LAZAROVITS G; NORTHCOTT D; STURZ AV. 1999. Behavior of plant material issued from in vitro tuberization. Potato Research 42: 505-519.
PAES APM; SILVA JX. 2003. A importância da qualidade da batata-semente na redução do custo de produção. In: SEMINÁRIO MINEIRO DE BATATICUlturA, 4. Anais... Poços de Caldas: Editora Gráfica Irmão Gino. p. 55-58.

ROETTGER DJ. 1987. Seed potato production in the Philippines. The Philippines: Eschborn. $114 \mathrm{p}$.

SOUZAZS. 2003. Ecofisiologia. In: PEREIRAAS; DANIELS J. O cultivo da batata na região sul do Brasil. Brasília: EMBRAPA. 567 p. 